\title{
Família e cuidado: uma análise a partir da Unidade Pediátrica do Hospital Universitário
}

\author{
Family e care: an analysis from the Pediatric Unit of the University Hospital
}

\author{
Deise Olidia Gonçalves * \\ Michelly Laurita Wiese **
}

\section{Resumo:}

O presente artigo busca dar visibilidade à discussão da caracterização das famílias de crianças com doenças respiratórias internadas na Unidade de Internação Pediátrica de um Hospital Universitário da região sul do Brasil e problematizar as potencialidades e dificuldades enfrentadas pela família no que se refere aos cuidados com a saúde e proteção de seus filhos (as). Trata-se de uma pesquisa com abordagem qualitativa, tendo como instrumento de coleta de dados a entrevista semiestruturada realizada com oito famílias de crianças internadas na Unidade Pediátrica do HU/UFSC em 2016. Os resultados apontam que são reconhecidas duas categorias temáticas: dinâmica e rede de apoio familiar; acesso aos serviços de saúde e medicamentos que interferem diretamente nas possibilidades de cuidado por parte dos familiares, podendo comprometer as condições de saúde da criança com doença.

Palavras-Chave: Criança. Cuidado em saúde. Doença respiratória. Família. Política social.

\begin{abstract}
:
This article aims to give visibility to the discussion of the characterization of the families of children with respiratory diseases hospitalized at the Pediatric Internment Unit of a University Hospital in the southern region of Brazil and to question the potentialities and difficulties faced by the family with regard to health care and protection of their children. It is a qualitative research, with a semistructured interview conducted with eight families of children hospitalized at the Pediatric Unit of the HU/UFSC in 2016. The results indicate that two thematic categories are recognized: dynamics and network family support; access to health services and medicines, which directly interfere with the possibilities of care by the relatives, and may compromise the health conditions of the child with illness.
\end{abstract}

Keywords: Child. Health care. Respiratory disease. Family. Social policy.

\footnotetext{
* Assistente Social. Hospital Universitário Professor Polydoro Ernani de São Tiago - (HU/UFSC). E-mail: deiseufscss@hotmail.com

** Doutora em Serviço Social. Docente do curso de Serviço Social da Universidade Federal de Santa Catarina. Email: michelly.wiese@ufsc.br
} 


\title{
Introdução
}

As profundas alterações políticas, econômicas e sociais que marcam a sociedade brasileira, no atual cenário neoliberal, têm trazido para o universo das famílias uma série de desafios, responsabilidades e também vulnerabilidades que assolam o cotidiano de suas vidas. Para Oliveira (2009) as alterações na instituição família são percebidas e decorrentes das mudanças ocorridas no campo econômico, nos processos de trabalho e nas relações sociais em geral, entre os quais se destacam: a industrialização, a expansão do mercado consumidor, a incorporação da mulher na esfera do trabalho remunerado, o avanço nas técnicas de controle da natalidade e o movimento feminista.

Mioto (1997) evidencia que, na medida em que as famílias não conseguem encontrar soluções para garantir as necessidades mínimas, elas podem expressar suas dificuldades por meio de inúmeras situações. As famílias têm de enfrentar circunstâncias como o desemprego, falta de habitação e a não efetividade de serviços públicos que tendem a contribuir às condições de vida, o que dificulta ou impossibilita que as famílias consigam exercer seu papel de proteção a seus membros, tais como o cuidado com a saúde, educação, entre outros. Neste sentido:

\begin{abstract}
A família se encontra muito mais na posição de um sujeito ameaçado do que de instituição provedora esperada. E considerando a sua diversidade, tanto em termos de classes sociais como de diferenças entre os membros que a compõem e de suas relações, o que temos é uma instância sobrecarregada, fragilizada e que se enfraquece ainda mais quando the atribuímos tarefas maiores que a sua capacidade de realizá-las (CAMPOS; MIOTO, 2003, p. 183).
\end{abstract}

No Brasil a atuação mínima do Estado no campo social tem contribuído para aumentar à visibilidade da família, enquanto, espaço primordial no cuidado e proteção de seus membros. Logo, é fundamental que essa revalorização da família não se constitua um mecanismo de redução da proteção social exercida pelo Estado, visto que somente pode se reivindicar à função protetiva da família na medida em que se entende, que ela também necessita de proteção e de amparo. Segundo Carvalho (2000, p. 18), "o potencial protetivo e relacional aportado pela família, em particular daquelas em situação de pobreza e exclusão, só é passível de otimização se ela própria recebe atenções básicas".

Neste sentido, o artigo objetiva dar visibilidade à discussão da caracterização das famílias de crianças com doenças respiratórias internadas na Unidade de Internação 
Pediátrica de um Hospital Universitário da região sul do Brasil e problematizar as potencialidades e dificuldades enfrentadas pela família no que se refere aos cuidados de saúde e proteção de seus filhos(as).

O interesse por esta temática é oriunda das experiências vivenciadas a partir da Residência Integrada Multiprofissional em Saúde, realizada entre os anos de 2015 a 2017, como Residente de Serviço Social com Ênfase na Saúde da Mulher e da Criança em um hospital universitário, sendo a imersão na Unidade de Internação Pediátrica.

Este estudo parte da necessidade de uma leitura crítica que considere que a qualidade de vida das famílias depende da articulação que cada uma consegue fazer diante das demandas internas (necessidades de seus membros nos diferentes estágios de desenvolvimento) e as demandas advindas de seu espaço social; ou seja, a capacidade de cuidado e de proteção depende das condições sociais, econômicas e culturais de cada família.

Nesta direção, é salutar, explicitar com base em Mioto (1997), que na contemporaneidade, "não é possível falar em família, mas sim famílias". O uso do plural objetiva abarcar, dentro da concepção de família, a diversidade de arranjos familiares na sociedade brasileira.

A família pode ser definida como um núcleo de pessoas que convivem em determinado lugar, durante um lapso de tempo mais ou menos longo e que se acham unidas (ou não) por laços consanguíneos. Ela tem como tarefa primordial o cuidado e a proteção de seus membros, e se encontra dialeticamente articulado com a estrutura social na qual está inserido (MIOTO, 1997, p. 120).

Abre-se, conforme Alencar (2008), para um caminho de novas configurações familiares que vão desde famílias monoparentais, decorrentes de separações ou abandonos; famílias formadas a partir de uniões livres; e até mesmo famílias formadas por pessoas convivendo no mesmo espaço, sem vínculos de aliança ou consanguinidade, mas com ligações afetivas de mútua dependência e responsabilidade.

Relacionando à discussão no campo da saúde, desde os anos 1990, em maior escala, as famílias vem sendo incorporadas nos sistemas de saúde como parceiras nos processos de provisão e oferta do cuidado em saúde a seus membros. Tal incorporação se deu através de dispositivos e mecanismos que explicitaram a família como fundamental ao processo de cuidado nos serviços de saúde, principalmente através de normativas que se 
refletem diretamente na estrutura e na provisão dos serviços (CAETANO; MIOTO, 2012; SILVA, 2016).

No que se refere às internações na unidade pediátrica, o cuidado à saúde se dá a partir da assistência prestada pela equipe que acompanha a criança e também de seu acompanhante. Na rotina da unidade, o acompanhante é inserido no cuidado, como dar banho, alimentação, entre outras tarefas. Neste sentido, entende-se que a função de cuidar exige um trabalho familiar entendido,

[...] Como o conjunto de atividades relacionadas às tarefas domésticas; ao cuidado de seus membros, especialmente os dependentes; e também os investimentos que as famílias têm de fazer no campo das relações com outras instituições que the exigem tempo, energia e habilidades" (MIOTO; DAL PRÁ, 2015, p. 150).

E ainda que:

Na saúde, um exemplo emblemático é o hospital. Um serviço que teoricamente dispensa a responsabilidade do usuário enquanto for necessária a internação. Porém, observa-se cada vez mais a requisição do trabalho da família, quer seja para assisti-lo à noite, para alimentá-lo, para trocar fraldas, para medicá-lo e, com isso, emergindo à exigência de cuidados cada vez mais sofisticados (MIOTO, 2012, p. 131).

A referida autora acrescenta que a presença da família é mais acionada na medida em que se verifica a defasagem de profissionais e as insuficiências existentes nos serviços de saúde. Entretanto, esta requisição nem sempre se relaciona às deficiências do serviço.

Para Silva (2016), a família permanece privada do suporte necessário para garantir o provimento do bem-estar. O Estado, em contrapartida, ao deixar de assegurar a proteção social em âmbito universal, aposta cada vez mais em políticas seletivas e fragmentadas, utilizando-se de mecanismos de solidariedade como forma de reduzir mais a dependência da família dos serviços públicos.

A partir da problematização inicial do tema, o artigo está organizado em quatro itens, sendo o primeiro a metodologia da pesquisa; o segundo destaca a caracterização das famílias entrevistadas; o terceiro traz a discussão da dinâmica e rede de apoio familiar na internação; e, no quarto item, o debate sobre o acesso à saúde e seus serviços. Para finalizar, são apontadas as considerações finais sobre o estudo efetuado. 


\section{Metodologia}

O presente estudo de caráter exploratório tem base na pesquisa qualitativa porque "[...] ela trabalha com o universo de significados, motivos, aspirações, crenças, valores e atitudes, o que corresponde a um espaço mais profundo das relações dos processos e dos fenômenos que não podem ser reduzidos à operacionalização de variáveis" (MINAYO, 1998, p. 21-22).

O campo de coleta foi a unidade de internação pediátrica de um Hospital Universitário da região sul do Brasil. Atualmente dispõe de 20 leitos para internação, que se dividem em: 04 lactentes ocupados por crianças em fase de amamentação, 08 pré-escolares ocupados por crianças que se encontram na faixa etária entre 01 a 05 anos, e 08 escolares ocupados por crianças com faixa etária entre 06 a 14 anos incompletos. Possui uma equipe multiprofissional composta por: médico, enfermeiro, nutricionista, fonoaudiólogo, fisioterapeuta, psicólogo, e assistente social. Encontra-se direcionada ao atendimento dos casos que não necessitam de Unidade de Terapia Intensiva, tendo como maior demanda de internação as doenças do sistema respiratório, tais como: asma, bronquiolite, pneumonia, entre outras ${ }^{1}$.

Para o desenvolvimento da pesquisa, realizou-se uma revisão de literatura sobre o tema. Como instrumento de coleta de dados, foi utilizada a entrevista semiestruturada. As entrevistas foram realizadas entre Agosto e Setembro de 2016.

De acordo com Minayo (1998), a entrevista é a técnica mais usada no trabalho de campo porque privilegia à coleta de informações e possibilita que a fala possa ser "reveladora de condições estruturais, de sistemas de valores, normas e símbolos [...] e ao mesmo tempo ter a magia de transmitir, através de um porta-voz, as representações de grupos determinados, em condições históricas, socioeconômicas e culturais específicas" (MINAYO, 1998, p. 109).

A definição dos sujeitos de pesquisa partiu do total de famílias de crianças internadas na Unidade Pediátrica do Hospital Universitário nos meses de Agosto a Setembro de 2016, que totalizou em 50 famílias. Deste total, foram escolhidas intencionalmente oito

\footnotetext{
${ }^{1}$ As doenças que acometem as vias respiratórias são responsáveis por grande parcela de adoecimento e morte em adultos e crianças, alterando os coeficientes de mortalidade infantil e sobrecarregando os serviços de assistência à saúde. Denomina-se doenças respiratórias infantis o conjunto de doenças de etiologia e gravidade diversas que comprometem uma ou mais porções do trato respiratório da criança. (NATALI et al., 2011).
} 
famílias de crianças com doenças respiratórias internadas na Unidade de Internação Pediátrica. A amostra foi intencional porque estas famílias podem ser identificadas através da existência dos prontuários físicos, na passagem de plantão da equipe de enfermagem, como também nos registros no Sistema de Administração Hospitalar, onde o setor de Serviço Social realiza o registro dos atendimentos. Para a coleta da pesquisa foi realizado atendimento pelo Serviço Social à família, sendo identificados os critérios de inclusão. Posteriormente foi realizado convite, apresentado o termo de consentimento para a realização da entrevista.

Partiu-se de critérios de inclusão para a composição da amostra assim definidos: as famílias de crianças com mais de uma (01) internação por doenças respiratórias; a/o entrevistada/o ser o responsável legal da criança internada; a pessoa entrevistada compor o grupo familiar da criança.

Após a coleta dos dados, foi realizada a análise das informações levantadas para encontrar as respostas às questões planejadas e assim confirmar ou não as hipóteses anteriormente estabelecidas. Diante disso, a análise de conteúdo contemplou as “[...] seguintes fases: pré-análise, exploração do material, tratamento dos resultados obtidos e interpretação" (MINAYO, 2008, p. 76).

Para a análise dos material obtidos a partir da entrevista, utilizou-se a interpretação dos dados, em que se elencaram os eixos temáticos mais presentes nas entrevistas. De acordo com Minayo (2008, p. 100), é preciso “(a) buscar a lógica interna dos fatos, dos relatos e das observações; (b) situar os fatos, os relatos e as observações no contexto dos atores; (c) produzir um relato dos fatos em que seus atores nele se reconheçam."

Os dados obtidos com a pesquisa possibilitaram subsidiar à reflexão crítica acerca da família de crianças com doenças respiratórias no contexto de internação hospitalar e contribuiu para o debate teórico acerca da temática.

Destaca-se que todos os processos da pesquisa de campo responderam aos critérios estabelecidos pela Resolução CNS 466/2012, que trata da ética em pesquisa com seres humanos. A pesquisa teve aprovação pelo Comitê de Ética em pesquisa da Universidade Federal de Santa Catarina, sob parecer número 1.622.456. 


\section{Resultados e Discussão}

Para iniciar a análise dos dados da pesquisa partiu-se das entrevistas realizadas com oito famílias das crianças internadas com doenças respiratórias na Unidade de Internação Pediátrica do HU/UFSC, destaca-se o quadro abaixo, que expressa o sexo, idade e procedência do membro da família entrevistado.

Quadro 1 - Sexo, idade e procedência da familiar entrevistada na UIP do HU/UFSC

\begin{tabular}{|l|c|c|l|}
\hline \multicolumn{1}{|c|}{$\begin{array}{c}\text { Famílias } \\
\text { entrevistadas }\end{array}$} & Sexo & Idade & \multicolumn{1}{|c|}{ Procedência } \\
\hline Familiar 01 & F & 34 & Florianópolis \\
\hline Familiar 02 & F & 29 & Biguaçu \\
\hline Familiar 03 & F & 27 & Florianópolis \\
\hline Familiar 04 & F & 26 & Palhoça \\
\hline Familiar 05 & F & 30 & Florianópolis \\
\hline Familiar 06 & F & 39 & São Jose \\
\hline Familiar 07 & F & 24 & Palhoça \\
\hline Familiar 08 & F & 29 & Florianópolis \\
\hline
\end{tabular}

Fonte: Elaboração das próprias autoras (2016).

As entrevistas foram realizadas, em sua totalidade, com o responsável legal do sexo feminino, sendo que a faixa etária ficou entre 24 a 39 anos de idade. Todas as entrevistadas eram mães de crianças em internação hospitalar, com crianças diagnosticadas às seguintes doenças respiratórias: Bronquiolite, Bronquite, Asma, Pneumonia e Hiper-reatividade Brônquica.

Quanto à procedência das famílias, percebeu-se que a maioria reside no município de Florianópolis. A procura das famílias dos outros municípios que compõem a grande Florianópolis decorre da falta de estrutura para atender às crianças com doenças respiratórias, nestes locais onde a procura da família para atendimento da criança ocorre a partir da demanda espontânea ou através de transferência de outros hospitais que não possuem atendimento pediátrico, mais especificamente das doenças respiratórias.

É importante destacar a prevalência da mulher no cuidado com as crianças internadas. "O papel da mulher para cuidar é uma construção social ideologicamente determinada, o que se constitui em uma obrigação moral" (NEVES; CABRAL, 2008, p. 553). Esta percepção também é expressa nas seguintes falas: 
Sou eu, a mãe, principalmente assim eu não abro mão de passar as noites com ela, porque desde a primeira internação eu acompanhei todo esse processo. (Família 01 [depoimento oral gravado. Agosto de 2016]).

Só eu, sempre eu, porque ninguém pode vim porque todo mundo trabalha, não pode perder o serviço. (Família 02 [depoimento oral gravado. Agosto de 2016])

Só eu mesmo [...]. Não que eu não confio, mas eu quero saber o que ta acontecendo. (Família 05 [depoimento oral gravado. Setembro de 2016])

É com frequência que se presencia em ambientes hospitalares, e em especial, em unidades pediátricas, a presença das mães nos processos de acompanhamento das internações. É difícil encontrar a substituição pela figura do pai ou de alguma outra pessoa da família ou não. Destaca-se que existem funções no interior das famílias e, conforme Teixeira (2008), estas também são historicamente constituídas ao longo do tempo e ganharam peculiaridades em cada formação socioeconômica.

Os estudos de Beuter et al. (2009, p. 30), apontam que:

[...] a ação de cuidar ultrapassa o âmbito familiar, estendendo-se ao espaço hospitalar. Por isso é visível identificar que "a construção da identidade de gênero é socialmente determinada; à mulher cabe o cuidado com a casa, com o cônjuge e com os filhos."

Quando se analisa a relação de vínculo de trabalho, renda familiar e situação de moradia das famílias entrevistadas têm-se as seguintes informações conforme quadro abaixo:

Quadro 2 - Vínculo de trabalho, renda familiar e situação de moradia das famílias entrevistadas na UIP do HU/UFSC.

\begin{tabular}{|c|c|c|c|}
\hline Famílias Entrevistadas & $\begin{array}{c}\text { Vinculo de } \\
\text { Trabalho }\end{array}$ & Renda Familiar & Situação de Moradia \\
\hline Familiar 01 & Formal & 1 a 3 salários mínimos & Cedida \\
\hline Familiar 02 & Desempregada & 1 a 2 salários mínimos & Alugada \\
\hline Familiar 03 & Informal & 1 a 2 salários mínimos & Própria \\
\hline Familiar 04 & Formal & 2 a 3 salários mínimos & Própria \\
\hline Familiar 05 & Desempregada & 1 a 2 salários mínimos & Própria \\
\hline Familiar 06 & Informal & 2 a 3 salários mínimos & Cedida \\
\hline Familiar 07 & Desempregada & 1 a 2 salários mínimos & Cedida \\
\hline Familiar 08 & Estudante & 1 a 2 salários mínimos & Cedida \\
\hline
\end{tabular}

Fonte: Elaboração das próprias autoras, 2016. 
No que se refere ao vínculo de trabalho das entrevistadas, o quadro acima demonstra que: 02 acompanhantes possuem vínculo formal de trabalho, sendo 01 operadora de caixa e 01 coordenadora de uma Casa Lar; 02 possuem vínculo informal: 01 diarista e 01 trabalha auxiliando o esposo com fotografia para eventos; 03 estão desempregadas; 01 encontra-se concluindo os estudos.

As entrevistadas desempregadas destacam que um dos motivos de não estarem inseridas no mercado de trabalho seriam às recorrentes internações de seus filhos(as), que apresentam as doenças respiratórias como diagnóstico dessas internações. Importante ressaltar que todas as famílias entrevistadas tiveram seus filhos(as) internados(as) no mínimo duas vezes.

Outro dado relevante, também apontado pelas entrevistadas, foi a orientação médica para a não inserção das crianças na creche, pois esse fator influenciaria a condição de saúde da criança, podendo ocasionar outras internações. Consequentemente, as mães permanecem em casa realizando as tarefas domésticas e cuidando de seus filhos(as). Este fato se afirma quando:

Na verdade, fica assim mais ou menos igualitário, sabe? Porque como meu marido é autônomo, então tem vezes que eu ganho mais. Eu tenho salário fixo, tem vezes que ele tira um pouco mais que eu. Então tem assim uma divisão, não dá pra dizer que ele é fixo ou eu, sabe? (Família 01 [depoimento oral gravado. Agosto de 2016])

Até agora era bem dividido, vamos dizer assim, a partir de agora provavelmente é $o$ pai que vai bancar a casa. (Família 06 [depoimento oral gravado. Agosto de 2016])

Os relatos evidenciam como as situações de saúde/doença interferem na dinâmica familiar bem como na inserção e continuidade ou não da mulher no mercado de trabalho. 0 cuidado dispendido aos filhos, em caso de repetidas internações hospitalares, interfere na garantia de permanência no mercado de trabalho repercutindo diretamente na renda da família.

Por isso, o cuidado executado pela família "é caracterizado por ações e por interações presentes no núcleo familiar, direcionado a cada um de seus membros, com o intuito de alimentar e fortalecer o seu crescimento, o seu desenvolvimento, a sua saúde e seu bem-estar [...]" (OLIVEIRA; MARCON, 2007, p. 68); mesmo que isso traga rebatimentos nos projetos individuais de cada membro familiar. 


\section{Dinâmica e Rede de Apoio Familiar na Internação}

$\mathrm{Na}$ internação hospitalar, as famílias se deparam à necessidade de reorganização para definir qual membro irá acompanhar a criança. Muitos fatores influenciam essa decisão, como, por exemplo, se haverá a possibilidade de revezamento ou não e quem permanecerá em casa com os demais filhos.

Evidencia-se, a partir da pesquisa, que é o membro do sexo feminino que permanece no acompanhamento da criança, mais especificamente a mãe da criança, como também o revezamento se dá em sua maioria com familiares do sexo feminino.

Com base em Guedes e Daros (2009, p. 123), há uma construção social burguesa, naturalizada e moralista que coloca o ato de cuidar como algo constitutivo e exclusivo das mulheres. Num discurso pautado no "altruísmo e na maternagem presentificam-se no cotidiano das mulheres, [...] a [...] dupla jornada de trabalho."

É possível perceber na rotina da unidade que o papel da família no cuidado, mas especificamente da mulher, se faz presente na internação da criança, que é vista com normalidade pela equipe, ou seja, faz parte da rotina da unidade, quando isso não ocorre a mãe é vista como aquela que "não sabe cuidar".

Neste sentido, constata-se a partir dos relatos das oito famílias entrevistadas, que a maioria dispõe de rede de apoio na unidade hospitalar e fora dela. Estas famílias em particular vivenciaram à experiência da internação de seus filhos(as) com doenças respiratórias por diversas vezes. Este fator faz com que as famílias já conheçam a equipe da unidade, sua rotina, etc. Percebeu-se durante o período de internação que geralmente se da em média entre 07 a 10 dias, o desconforto da família em relação à equipe pelo fato da criança ter sido internada mais de uma vez. Muitas das famílias se sentiam culpadas em decorrência das internações.

Aqui se apresenta a relação da família com a equipe de saúde. Mesmo com a existência da política de humanização nos serviços de saúde, "as pessoas, no hospital, ficam expostas a um ambiente estranho e impessoal, onde o relacionamento dos profissionais de saúde com elas caracteriza-se pela distância, formalidade, informações rápidas e a utilização de terminologias técnico-científicas." (BEUTER, 1996, p. 16). 
Além disso, os relatos enfatizam que, em decorrência das internações da criança, surge a necessidade da família se organizar no que se refere ao revezamento do acompanhamento, como retratam as falas a seguir:

Sim, com a madrinha dele. Na primeira vez que ele ficou internado eu revezei com a minha irmã e agora eu revezei com a madrinha. (Família 04 [depoimento oral gravado. Setembro de 2016]).

Nessa internação agora minha sogra, avó paterna, acompanhou durante vários períodos, pai ficou um pouquinho com ela e a minha mãe também ficou um período com ela. Na primeira internação, foi só eu e meu marido. (Família 06 [depoimento oral gravado. Agosto de 2016]).

Fica assim, como eu passo as noites aqui no hospital, [...] sem querer acaba dividindo, assim eu mais com a atenção pra Ana e o pai um pouco mais de atenção com o Lucas, a minha mãe acaba ajudando aqui, mas ela também se divide, às vezes ela vai lá em casa pra lavar uma roupa, ver como eles estão, mas dai acaba que o Lucas fica um pouco mais aos cuidados do pai. (Família 01 [depoimento oral gravado. Agosto de 2016])

A minha mãe foi fundamental porque dai na outra vez ela deu todo o apoio que precisava também pro meu marido em casa. Minha sogra dessa vez ajudou muito, meu pai também tudo que precisa ir, buscar, trazer, meu pai sempre é meu parceiro. (Família 06 [depoimento oral gravado. Agosto de 2016])

Diante da situação de saúde e internação da criança, surge à necessidade da família solicitar apoio à família extensa, como também para auxilio ao cuidado com os demais filhos, quando há. A partir dos relatos trazidos pelas famílias no que se refere à rede de apoio, fica evidenciado que as famílias que conseguem construir sua rede de apoio familiar e/ou informal tendem a se reorganizar diante do tempo de internação da criança. A família que conta com uma rede de apoio familiar dispõe de maior flexibilidade durante a internação, seja no auxílio no revezamento do acompanhamento da criança internada, seja no auxílio dos cuidados com os demais filhos, bem como nas necessidades que a família tem durante a internação.

Também há famílias que, além de não contar com o apoio da rede de saúde pública, não dispõem de um membro da família e/ou amigos disponíveis para revezar o acompanhamento à criança durante a internação. Percebeu-se que apenas duas famílias não dispõem de apoio no revezamento com familiares, amigos, entre outros. Esta percepção se reflete nas duas falas a seguir:

Sempre é eu que fico e meu pai e minha mãe sempre tão vindo, traz o que eu preciso ou a minha irmã depende. (Familia 03 [depoimento oral gravado. Setembro de 2016]). 
Só eu, sempre eu, porque ninguém pode vim porque todo mundo trabalha não pode perder o serviço ai final de semana ta todo mundo cansado ninguém quer vim e dai tem que ser eu. (Família 02 [depoimento oral gravado. Agosto de 2016]).

Fica explícito que a família que dispõe de uma rede de apoio familiar lida com a internação de maneira mais tranquila. Já as famílias que não podem contar com uma rede de apoio para o revezamento tendem a ficar desde o início ao fim da internação com apenas um acompanhante, especificamente a mãe da criança.

Outo dado a se considerar é a ausência de serviços sociais públicos que possam dar suporte às famílias no que tange aos cuidados e na garantia de condições a sustentação da dinâmica familiar diante de situações como as frequentes ausências das mulheres e mães do convívio familiar em decorrência das internações de seus filhos. Marcondes e Yannoulas (2012, p. 179) afirmam que "o fato de o cuidado não ser devidamente problematizado na agenda política do Estado permite que as necessidades de quem cuida e de quem é cuidado não sejam colocadas como uma questão política".

Em contrapartida, o que se presencia é o aumento de programas de atenção domiciliar em que os cuidados de saúde são assumidos em ambiente doméstico pela família, desresponsabilizando em certa medida, os serviços de saúde pelo cuidado direto e intensivo de seus usuários/pacientes². É possível identificar o caráter familista das políticas sociais e a insuficiência estatal que reitera a centralidade das famílias na questão do cuidado, difundindo a ideia de que as famílias conseguem desempenhar autonomamente à proteção social.

\section{Acesso à Saúde e Seus Serviços}

Neste item, destaca-se como se deu o acesso da família no que se refere aos serviços públicos para acompanhamento de saúde e acesso aos medicamentos necessários para o tratamento das crianças com doenças respiratórias.

Quanto ao acesso aos serviços de saúde, percebeu-se que, das oito famílias entrevistadas, apenas uma (01) delas informou que o acesso é somente pelo Sistema Único

2 Com a crise do modelo de atenção hospitalar brasileiro há um estímulo para o desenvolvimento de alternativas para a produção da integralidade na rede de serviços de saúde. Mesmo sem uma política formal ampla de financiamento de práticas assistenciais voltadas à desospitalização, inúmeras organizações de saúde vêm instituindo práticas baseadas na oferta de intervenções terapêuticas no interior do domicílio do usuário. (FEUERWERKER; MERHY, 2008, p. 181). 
de Saúde (SUS), visto que a criança, além de apresentar doença respiratória, tem diagnóstico de hidrocefalia, havendo a necessidade de acompanhamento com várias especialidades.

Ela tem acompanhamento, sim, é pelo SUS, né? Só que, assim, um é na policlínica, o outro é no infantil, né? Eu tenho que me localizar pra ir fazer esse tratamento, tipo, com a Neuro, com a Endócrino, Pediatra eu faço mesmo lá no bairro Biguaçu, tudo pelo SUS. E às vezes eu tenho que pagar o exame porque é necessário fazer e só, mas ela faz tratamento pelo SUS. (Familia 02 [depoimento oral gravado. Agosto de 2016])

Percebeu-se também a partir desta fala que, embora o acesso seja gratuito, a família tem dificuldade de se locomover para acessar os serviços, que não se concentram em apenas uma instituição para o acompanhamento da criança. "Dessa forma, o uso dos serviços requer das famílias a organização de seu tempo e de seus recursos" (MIOTO, DÁL PRA, 2015, p. 152).

Outro aspecto importante a ser destacado é que as famílias, dependendo da região em que moram, têm o acesso ao acompanhamento com pediatra ou médico da família nas unidades de saúde de seu bairro, sendo que, para algumas, esse acesso se torna mais difícil. Isto fica evidenciado com a fala da Família 08:

\begin{abstract}
Não realiza acompanhamento [...]. Tá complicado pra mim, tô tentando se virar pra conseguir um especialista, porque pra mim é ruim, né?, do jeito que ele fica. Agora que ele tá acompanhando aqui com pediatra, lá não tem, ele teve que vim transferido pra cá. Ele fez acompanhamento de saúde até os 07 meses, daí com 08 já não tinha, 09 já não tinha, porque não tinha médico. Às vezes ela faltava, não tinha vaga. (Família 08 [depoimento oral gravado. Setembro de 2016])
\end{abstract}

Embora conste no Estatuto da Criança e do Adolescente (ECA), de 1990, em seu artigo 70, "A criança e o adolescente têm direito a proteção à vida e à saúde, mediante a efetivação de políticas sociais públicas que permitam o nascimento e o desenvolvimento sadio e harmonioso, em condições dignas de existência" (BRASIL, 1990), observa-se, através das falas das famílias entrevistadas, que este acesso não atinge aos princípios do SUS:

Em específico até agora não. Ela faz os acompanhamentos com a pediatra né?, consultas de rotina anual, no posto de saúde ela tá fazendo, [...] mas aí agora a médica hoje sugeriu pra ter um acompanhamento com pneumo. [...] De repente, nesse primeiro momento, a gente vai no particular pra acompanhar, né?, não deixar descoberto esse acompanhamento, mas eu vou entrar com a solicitação via posto de saúde, sim. (Família 06 [depoimento oral gravado. Agosto de 2016]).

Então, eu tinha já de uma outra vez eu tinha consultado um pneumologista, mas devido eu não ter plano de saúde e a consulta ser cara eu consultei mais por 
questão emergencial, ela consulta pediatra, né?, é particular. Mas o indicado seria com pneumologista pra poder fazer todo o acompanhamento adequado assim, né? (Família 01 [depoimento oral gravado. Agosto de 2016]).

Acompanha com pneumologista. É privado, agora é privado, mas já foi público. Na primeira foi público, depois foi particular, com plano médico. [...] Como ele sempre tem essas crises, a gente resolveu colocar ele pra particular. (Família 03 [depoimento oral gravado. Setembro de 2016])

A partir das falas trazidas pelas famílias, percebemos que o acesso aos serviços de saúde para a criança não garante um acompanhamento adequado no que se refere às doenças respiratórias, visto que esse acompanhamento deveria se dar com o pneumologista, tendo a família dificuldade de conseguir garantir este atendimento pelo SUS.

A família que consegue custear este profissional via setor privado consequentemente proporciona condições à criança realizar o devido acompanhamento, que deveria também ser garantido pelo Estado. "O atendimento das necessidades de saúde dos usuários leva-os a buscar os caminhos e os serviços que lhes dão acesso ao atendimento de sua demanda" (BARROS; SÁ, 2010, p. 2477).

Sendo assim, não se trata de buscar explicações sobre o porquê de as famílias procurarem os serviços de saúde privados para o acompanhamento de seus filhos(as), mas identificar que os serviços públicos de saúde não estão sendo capazes de acolher e dar seguimento adequado às demandas em tempo capaz de ser tolerado pelas famílias de crianças com doenças respiratórias.

Atualmente, no município de Florianópolis, existem apenas duas instituições onde são realizados acompanhamentos com pneumologista: o HU/UFSC conta com 01 profissional; o Hospital Infantil Joana de Gusmão conta com apenas 02 pneumologistas, sendo este último referência para Santa Catarina. Esta quantidade de profissionais não dá conta da demanda de acompanhamento das crianças com doenças respiratórias. Para que a criança seja atendida pelo pneumologista é necessário que o pediatra ou médico da família que acompanha a criança primeiramente perceba a necessidade de fazer o encaminhamento, para que a família posteriormente solicite à Unidade Básica de Saúde o agendamento para a criança.

A dificuldade da família em acessar ao atendimento para seus filhos(as) com pneumologista é evidente nas falas retratadas nas entrevistas, como também quando a 
criança chega à unidade para mais uma internação, constatando assim a ineficaz atuação da rede de saúde.

No que se refere ao acesso aos medicamentos para o tratamento das doenças respiratórias, as famílias relatam que o mesmo ocorre de maneira acessível, sendo que a maioria afirma conseguir pelo SUS os medicamentos. Em alguns casos, a família compra o medicamento.

\section{Considerações Finais}

A participação do responsável pelo cuidado da saúde à criança hospitalizada se manifesta de várias formas. Há famílias que, por terem acompanhado a criança por diversas vezes, já conhecem a rotina da unidade e a equipe. É importante que os profissionais não tenham atitudes que tendam a culpabilizar as famílias devido a várias internações. Por isso, a comunicação entre os profissionais e a família é fundamental, possibilitando haver a redução da ansiedade dos pais, visto que é uma atitude que tende a favorecer a adesão aos tratamentos, ao processo de enfrentar a doença e ao de autonomia dos pais.

Cabe ao SUS garantir de maneira concreta o acesso integral ao atendimento de saúde. Diante das informações coletadas na pesquisa, ficou explícito que as famílias não contam com a viabilização adequada ao acompanhamento das crianças com doenças respiratórias, sendo uma dificuldade ao acesso ao atendimento da criança com pneumologista, visto que a rede não dispõe de recursos humanos suficientes para atender à demanda, ocasionando uma longa espera da família para conseguir atendimento a seu filho(a). Essa questão influencia, de maneira direta, a dinâmica dessas famílias, que acabam, muitas vezes, perdendo o emprego ou também tendo de abrir mão de inserirem-se no mercado de trabalho para acompanhar a criança nas várias internações hospitalares devido ao diagnóstico de doenças respiratórias. Como muitas dessas famílias, conforme constatado na pesquisa, trabalham informalmente ou estão desempregadas devido à situação de saúde de seus filhos(as), esse fator tende a dificultar a família no que se refere à garantia de atenderem às suas necessidades básicas, em especial a garantia à saúde.

Foi constatado na pesquisa que os serviços de saúde ainda são frágeis no que diz respeito ao acompanhamento de crianças com doenças respiratórias. Diante deste fato, algumas famílias buscam alternativas para que o acesso ao tratamento seja de fato 
concretizado. Já as que não têm condições de pagar uma consulta particular ou não possuem um convênio médico, tem como a única alternativa entrar na lista de espera para atendimento à criança com doença respiratória.

Diante do exposto, percebeu-se que a família que tem melhores condições financeiras consegue garantir o acesso da criança à saúde, já que as que não dispõem dessas condições apresentaram mais dificuldades para garantir esse acesso.

Portanto, destaca-se a importância de que os profissionais de saúde, inclusive o Assistente Social, estejam atentos às necessidades, dificuldades e angústias vivenciadas pelas famílias de crianças com doenças respiratórias que chegam na unidade de internação hospitalar, buscando, a partir da assistência de saúde prestada, acolher, dar suporte e realizar os encaminhamentos possíveis pela equipe para que a família consiga garantir o acesso da criança à saúde.

É relevante destacar também à necessidade constante de estudos e pesquisas que evidenciem e aprofundem as análises das mais diversas expressões da questão social aqui manifestadas no campo da política e serviços de saúde bem como no âmbito das famílias.

\section{Referências}

ALENCAR, M. M. T. Transformações econômicas e sociais no Brasil dos anos 1990 e seu impacto no âmbito da família. In: SALES, M. A.; MATOS, M. C.; LEAL, M. C. (Org.). Política social, família e juventude: uma questão de direitos. 3. ed. São Paulo: Cortez, 2008.

BARROS, D. M.; SÁ, M. C. O processo de trabalho em saúde e a produção do cuidado em uma unidade de saúde da família: limites ao acolhimento e reflexos no serviço de emergência. Ciência e Saúde Coletiva, Rio de Janeiro, v. 15, n. 5, p. 2473-2482, 2010. Disponível em: <http://www.scielo.br/scielo.php?script=sci_arttext\&pid=S1413-81232010000500022>. Acesso em: 15 ago. 2016.

BEUTER, M. Atividade lúdica: uma contribuição para a assistência de enfermagem às mulheres portadoras de câncer. 1996. 172 f. Dissertação (Mestrado em Enfermagem) Universidade Federal de Santa Catarina, Florianópolis, 1996.

BEUTER, M. et al. Perfil de familiares acompanhantes: contribuições para a ação educativa da enfermagem. REME - Revista Mineira de Enfermagem, Belo Horizonte, v. 13, n. 1, p. 28 33, jan./mar., 2009. Disponível em: <http://www.enf.ufmg.br/site_novo/modules/mastop_publish/files/files_4c0e47a93ae90.p df>. Acesso em: 10 dez. 2016. 
BRASIL. Lei n. 8.069, de 13 de julho de 1990. Dispõe sobre o Estatuto da Criança e do Adolescente e dá outras providências. Disponível em:

<http://www.planalto.gov.br/ccivil_03/leis/L8069.htm>. Acesso em: 5 jan. 2016.

CAETANO, P. S.; MIOTO, R. C. T. A política de saúde e a participação da família nos serviços. In: ENCONTRO NACIONAL DE PESQUISADORES EM SERVIÇO SOCIAL (ENPESS) - Serviço social, acumulação capitalista e lutas sociais: o desenvolvimento em questão, 13., 2012. Juiz de Fora. Anais... Juiz de Fora, 2012. CD-ROM.

CAMPOS, M. S.; MIOTO, R. C. T. Política de Assistência Social e a Posição da Família na Política Social Brasileira. Serviço Social, Brasília, n. 12, p. 165-190, jan./jun. 2003.

CARVALHO, Maria do Carmo Brant de (Org.). A família contemporânea em debate. 3. ed. São Paulo: Cortez, 2000.

FEUERWERKER, L. C. M.; MERHY, E. E. A contribuição da atenção domiciliar para a configuração de redes substitutivas de saúde: desinstitucionalização e transformação de práticas. Revista Panamericana de Salud Publica, Washington, v. 24, n. 3, p. 180-188, 2008. Disponível em: <http://www.scielosp.org/pdf/rpsp/v24n3/a04v24n3>. Acesso em: 4 out. 2017.

GUEDES, O. S.; DAROS, M. A. O cuidado como atribuição feminina: contribuições para um debate ético. In: Serviço Social em Revista, Londrina, v. 12, n. 1, p. 122-134, jul./dez. 2009. Disponível em:

<http://www.uel.br/revistas/uel/index.php/ssrevista/article/viewFile/10053/8779>. Acesso em: 21 fev. 2018.

MARCONDES, M. M.; YANNOULAS, S. C. Práticas sociais de cuidado e a responsabilidade do estado. Revista Ártemis, João Pessoa, v. 13; jan./jul., p. 174-186, 2012. Disponível em: <http://periodicos.ufpb.br/ojs/index.php/artemis/article/view/14222/8150>. Acesso em: 21 fev. 2018.

MINAYO, M. C. S. O Desafio do conhecimento: pesquisa qualitativa em saúde. 5. ed. Rio de Janeiro: ABRASCO, 1998.

MINAYO, M. C. S. et al. (Org.). Pesquisa social: teoria, método e criatividade. 27. ed. Petrópolis: Vozes, 2008.

MIOTO, R. C. T. Família e Serviço Social: contribuições para o debate. In: Revista Serviço Social e Sociedade, São Paulo, n. 55, p. 114-130, 1997.

MIOTO, R. C. T. Processos de responsabilização das famílias no contexto dos serviços públicos: notas introdutórias. In: SARMENTO, H. B. M. (Org.). Serviço Social: questões contemporâneas. Florianópolis: UFSC, 2012. v. 1.

MIOTO, R. C. T.; DAL PRÁ, K. R. Serviços sociais e responsabilização da família: contradições da Política Social brasileira. In: MIOTO, R.; CAMPOS, M.; CARLOTO, C. (Org.). Familismo, direitos e cidadania: contradições da política social. São Paulo: Cortez, 2015. p. 147-178. 
NATALI, R. M. T. et al. Perfil de internações hospitalares por doenças respiratórias em crianças e adolescentes da cidade de São Paulo, 2000-2004. Revista Paulista de Pediatria, São Paulo, v. 29, n. 4, p. 584-590, 2011. Disponível em:

$<$ http://www.scielo.br/scielo.php?script=sci_abstract\&pid=S0103-

$05822011000400018 \&$ lng=pt\&tlng=pt>. Acesso em: 10 dez. 2016.

NEVES, E. T.; CABRAL, I. E. Empoderamento da mulher cuidadora de crianças com necessidades especiais de saúde. In: Texto e Contexto Enfermagem, Florianópolis, v. 17, n. 3, p. 552-560, 2008.

OLIVEIRA, N. H. D. Recomeçar: família, filhos e desafios. São Paulo: UNESP, 2009. p. 65-107. Disponível em: < http://books.scielo.org/id/965tk>. Acesso em: 10 dez. 2016.

OLIVEIRA, R. G.; MARCON, S. S. Trabalhar com famílias no Programa de Saúde da Família: a prática do enfermeiro em Maringá-Paraná. Revista da Escola de Enfermagem da USP, São Paulo, v. 41, n. 1, p. 65-72, 2007. Disponível em

<http://www.ee.usp.br/reeusp/upload/pdf/304.pdf>. Acesso em: 5 jan. 2017.

SILVA, R. R. O processo de responsabilização familiar no cuidado de crianças internadas na pediatria do HU/UFSC. 2016. 73 f. Trabalho de Conclusão de Curso (Graduação em Serviço Social) - Universidade Federal de Santa Catarina, Florianópolis. 2016.

TEIXEIRA, S. M. Família e as formas de proteção social primária aos idosos. KAIRÓS Gerontologia, São Paulo, v. 11, n. 2, p. 59-80, 2008. 